\title{
LA RACIONALIDAD ACTUAL DE LOS DERECHOS HUMANOS: LO JURÍDICO, LAS CIENCIAS HUMANAS Y LA GUBERNAMENTALIDAD
}

\author{
Adrian Manzi \\ Universidad Nacional de San Luis, Argentina
}

http://dx.doi.org/10.5209/rev_NOMA.2013.v39.n3.48321

\begin{abstract}
Resumen.- El siguiente trabajo intenta reflexionar cómo los Derechos Humanos permiten que se establezca la relación entre saber y poder mediando tanto la objetivación del hombre como la subjetivación del mismo, pero acentuando la relación de los Derechos Humanos sobre la función del gobierno: la de conducir conductas de la población. Se toma como eje para esta reflexión lo desarrollado por Miche Foucault en los cursos del College de France entre 1975 y 1978, y sus últimas intervenciones políticas de 1982 y 1983 en relación con derechos de los gobernados.
\end{abstract}

Los derechos humanos son un mecanismo que es axiológico porque integra los aspectos universalistas de la vida, el trabajo y el lenguaje, y son mercantilistas porque reciben los impactos de una verdad que el mercado, que con su lógica de acumulación y producción inocula todo lo que toca. Es también jurídico porque determina la condición de los seres humanos, en tanto que persona individual, colectividad o minoría, y en tanto de nuevas tipologías y clasificaciones a considerar.

Las ciencias del hombre han brindado aportes a los espacios, han oxigenado a las relaciones de poder disciplinarias, las de opresión, las de vigilancia, la de medicalización, las de educación, las ecológicas, las políticas en general. Los derechos humanos, por su parte, han funcionado en todos estos ámbitos coercitivamente hacia el mismo saber penitenciario, médico, y jurídico.

Palabras Claves.- Derechos Humanos, Disciplina, Biopolítica, Biopoder, Gubernamentalidad, Ciencias Humanas, Subjetivación, Sublevación.

\section{Un Biopoder Mediador, unas Ciencias Humanas dialogantes.}

Integraremos a continuación el Aporte de Foucault acerca de las disciplinas y cómo los derechos humanos permiten que se establezca la relación entre saber-poder mediando tanto la objetivación del hombre como la subjetivación del mismo, pero acentuando la relación de los derechos humanos sobre la función del gobierno: la de conducir las conductas de la población. En el curso de 1976, "Defender la sociedad", Foucault desplegó su análisis genealógico del poder y tomó como "bisagra" a la población. Es cuando para él ingresó en su método de análisis la vida, pero ahora a nivel de masa, en la escena política. Sumó a la importancia de individualizar al cuerpo del hombre a través del saber disciplinar, el interés por el movimiento del ser humano en términos de "especie", es decir "la población". Comenzó en ese año a delinear lo que él entendió como "Biopolítica", conceptualizada ésta como:

(...) una nueva tecnología destinada a la multiplicidad de los hombres, pero no 
en cuanto se resumen en cuerpos sino en la medida que forma una masa global, afectada por procesos de conjunto que le son propios de la vida, como el nacimiento, la muerte, la producción, la enfermedad, etc. Es un ejercicio que no es individualizador, sino masificador, que no se dirige al hombre/cuerpo, sino al hombre/especie. (Foucault, 2000: 220).

La biopolítica tiene que ver con un conjunto de procesos en relación con toda una masa de población, vista como problema político, a la vez que científico, biológico y de poder.

La biopolítica cumple la función de ocuparse del carácter aleatorio inherente a la población, a los movimientos que proveen los fenómenos colectivos, que sólo se manifiestan en sus efectos económicos y políticos y que, por supuesto, tienen una duración considerable. Se amplía así la concepción del poder en cuanto a su tecnología, en tanto su economía. Una técnica disciplinaria por un lado, y una técnica de la vida que reagrupa los efectos de masa propios, donde los cuerpos se reubican en los procesos biológicos en conjunto, por otro. Se establece una nueva articulación coyuntural entre estas tecnologías; lo que él llamará luego "Biopoder".

Es viable decir que los derechos humanos, en tanto cooperadores de las cuadrículas disciplinarias y como técnica capaz de aglutinar una masa amorfa en su espontaneidad, cumplen con los requisitos para que un gobierno se ocupe lo mejor que pueda de su población, al menos que conozca, bajo algún aspecto, su dinámica en términos biológicos. Es esto y mucho más. Así como la sexualidad fue importante por muchas razones, pero en particular

(...) como conducta corporal, está en la órbita de un control disciplinario, individualizador, en forma de vigilancia permanente; y también se inscribe y tiene efecto, por sus consecuencias procreadoras, en unos procesos biológicos amplios que conciernen a esa unidad múltiple que constituye la población. Compete, por tanto, a la disciplina, pero también a la regulación (Foucault, 2000: 227);

Los derechos humanos cumplen igual función, e incluso incluyendo y cooperando en la disciplina y en la regularización en y de la sexualidad. La medicina, la psiquiatría, la psicología, la educación, los aparatos judiciales, los controles sociales, las prisiones, son a las disciplinas y a la regulación, lo que los derechos humanos son a la política y al equilibrio (regulación) social cuando éste manifiesta no lo alienado, lo enfermo, lo incapaz, lo anormal, lo peligroso, lo carente, sino, cuando manifiesta lo excluido económicamente, lo innombrable políticamente, a veces lo inclasificable jurídicamente, lo expropiado perversamente.

Dentro de esta función regulizadora es que es posible graficar gracias al conocimiento que se obtiene de todo aquello que es propio de la población, es decir, tasa de natalidad, de mortalidad, de enfermedades, emigración e inmigración, de alfabetización, de urbanización, de criminalidad, de indigencia y pobreza (y en el caso de la Argentina de detenciones-desapariciones). Se necesitan conocer los mecanismos y las lógicas, las tácticas y estrategias con que opera el poder en esta sociedad; de sus particularidades que tiene para actuar en aquellas situaciones en las que los sujetos están implicados en estos movimientos intrínsecos de la población, para así poder analizar cuáles tipos de subjetividades se promueven bajo una óptica de una objetivación ya 
preestablecida, que clasifica y jerarquiza, diferenciándolas de aquellas subjetividades que se van produciendo en el momento y que nacen en búsqueda de una subjetividad propia todavía no formada, no nombrada y en donde un sujeto puede emerger.

Las disciplinas, conjuntamente con la biopolítica, bajo este aspecto, aportan toda una tecnología y unos mecanismos que captan lo necesario para saber acerca de los movimientos propios de la población, pudiendo establecer una tasa de "normación" en cada aspecto por diferenciar, aportando a la economía del poder.

Lo primero y fundamental de la normalización disciplinaria no es lo normal y lo anormal, sino la norma. A causa del carácter prescriptivo de la norma en relación con lo normal, el hecho de que la normalización disciplinaria vaya de la norma a la diferenciación final de lo normal y lo anormal, lo que ocurre en las técnicas disciplinarias se trata más de una normación que de una normalización (Foucault, 2006: 76).

Pareciera ser que el conocimiento, el saber que los derechos humanos pudieran brindar, no sólo se utiliza para normalizar, sino más bien para sugerir la posibilidad de relacionarse con otros saberes tomando obligadamente una posición jurídica, económica y ética; sobre la vida, el trabajo y el lenguaje, es decir, sobre las dignidades de la vida y las formas de la muerte, la relación con la economía y las posibilidades de producir verdades.

Es por estas razones que se afirma, tal como expresa Foucault, que "la sociedad de normalización es una sociedad donde se cruzan, según una articulación ortogonal, la norma de la disciplina y la norma de la regulación" (Foucault, 2000: 229). Es la norma el elemento que circula entre lo disciplinario y lo regularizador. Y es el biopoder el que se hizo cargo del cuerpo y de la vida, o de la vida en sus dos aspectos fácilmente descriptibles: el cuerpo individual y la población.

Existen articulaciones por demás características de la sociedad argentina, para analizar y pensar los modos según los cuales el sujeto pudo ser insertado como objeto en los juegos de verdad, en aquellas relaciones en las que nace cierto "juego de verdad". Y es aquí donde la objetivación y la subjetivación son posibles, donde el hombre se propone observarse a sí mismo como espacio y dominio de un saber y de un hacer posible.

El hecho es que, por ejemplo, por cada muerto en circunstancias dudosas, extravagantes o nítidas, de desempleo masivo, de descontento general por algún motivo, o de festividad histórica y simbólica, se moviliza una gran cantidad de personas por un trayecto geográfico con valor simbólico o con sentido referencial por el mismo. Las movilizaciones se han convertido en una nueva relación de fuerza, ya que los espacios han cobrado un sentido político, es decir, una relación con valor de cierta verdad, en los que la disputa por los espacios eleva a la superficie lo que el discurso dominante niega o calla, desmiente o desvaloriza, ignora y culpabiliza.

Siguiendo esta línea de pensamiento, podríamos pensar que los derechos humanos, en tanto no se hagan cumplir y salgan a la luz a partir de las diferentes demandas en los términos más amplios posibles: judiciales, desde organismos diversos, desde reclamos sociales de las organizaciones, entre 
otros, conformarían, además de un elemento de las disciplinas, una técnica práctica de conocimiento que permitiría el registro y la regulación de la población y de la administración gubernamental.

En su función de Declaración Universal, devienen del orden de la violencia que ha sido ejercida a través de los tiempos, del hombre sobre el hombre mismo al decir de Hobbes (1588-1679): "el hombre es el lobo del hombre"; pero también han devenido del orden de la evolución en la cultura occidental, propia de su civilización. Llegando a conformar parte de la utopía a la que se espera alcanzar, entendida esta última como lugar factible por realizar. Se puede decir que nace de una matriz política y se articula como "derecho" al derecho, es decir, como saber-código, produciendo legislaciones y acciones, representaciones y conciencia, para luego depositar más saber sobre esta conciencia y sus representaciones. Pero además, y ya de lleno en la modernidad, posibilidad de actuación política y social, de mecanismos de relaciones de poder. Tal como citamos en capítulos anteriores, para Foucault (2000, 2002b) donde hay poder hay resistencia, y ésta nunca está en posición de exterioridad respecto del poder.

Para que exista "poder" tiene que haber libertad de acción. Donde las relaciones están saturadas (amo-esclavo) no hay relación de "poder". Por eso es que tanto en lo jurídico como en lo discursivo, como en lo disciplinario, se aboga por la libertad, por el mínimo espacio de libertad. Podemos observarlo a éstos en el ámbito de lo punitivo, donde una de las etapas finales de la pena es la libertad condicional que, por medio de un saber, "normaliza al individuo", subjetiviza al sujeto para que "vuelva" a la sociedad. También se lo puede observarlo en la manera en que se suministran fármacos en personas que padecen sufrimiento psíquico, donde la droga se suministra entre un activar y un relajar, para mantenerlo a raya, para que realice las funciones que se consideran mínimas para vivir, es decir, dormir, comer, descansar, trabajar sin caer en el exabrupto brote de la angustia. Y en el ámbito de lo social altamente carenciado en sus necesidades básicas, además de poder estar implicadas las dos acciones antes descriptas, se realiza una cobertura de asistencialismo que consiste en sostener no íntegra y totalmente, pero sí variada y multifacéticamente, a las personas desde lo alimenticio, lo edilicio, lo afectivo, lo judicial, lo extra-judicial por parte de lo que se llama la "asistencia social". Existe en las relaciones de poder un espacio en el que es posible ver y decir, un espacio en el que es factible que surja un hombre y en el cual cualquiera de nosotros puede estar allí.

Por ejemplo, en relación con la Ley No 24.660 de el Código Penal Argentino, observamos con claridad cómo el poder no deja de acentuar su relación a la vez que establece espacios en los que el diálogo técnico y acreditado parece atenuar lo que de asfixiante tiene esta misma relación (ver sección anexos). Este proceder es meritorio y bondadoso a la vez que es obligatorio. Permite tomar distancia a la vez que se sigue amarrado a él.

Las ciencias del hombre han brindado aportes a los espacios citados en el párrafo anterior, han oxigenado a las relaciones de poder disciplinarias, las de opresión, las de vigilancia, la de medicalización, las de educación, las ecológicas, las políticas en general. Los derechos humanos han funcionado en todos estos ámbitos coercitivamente hacia el mismo saber penitenciario, médico, y jurídico. Los derechos humanos proporcionan oxígeno ahí donde 
está próxima a saturarse la relación; no solamente otorgan subjetividad y actividad política, sino que otorgan la posibilidad de dinamizar las relaciones de poder, de ofrecer apertura de espacios y tiempos admisibles para que las relaciones existan, se entablen gracias a la posibilidad de emergencia de algo nuevo que es el conocimiento y son los discursos, liberando a los sujetos de sus padecimientos o sufrimiento terrenal o material; pero sujetándolos desde instancias "disciplinarias", disponiéndolo en algún sector funcional.

\section{El desprendimiento de un saber. Saber y poder.}

Lo que se intenta en este análisis es ver cómo, a través de múltiples prácticas, de variadas racionalidades e irracionalidades, se contribuye a construir la subjetividad, cuando la población entra a jugar bajo el amparo de los derechos humanos. Y si bien esta subjetividad se constituye, si bien bajo la máscara de una lucha de clases, con una racionalidad o estilo de práctica particular, con el objetivo de integrar a todos los ciudadanos en la lucha por "sus" derechos, por los derechos de todos, se hace imprescindible como proceso, salir a mostrarse y observarse, encontrándose con la mirada del otro semejante, que padece. Pero también mostrándole que cada uno, cada sector, puede quebrantar la libertad del otro de ejercer sus derechos hasta más comunes, como es el de circulación, el de comercio, el de hospitalizarse, el de educarse, el de trabajar, el de expresarse y hasta ser soberano del propio cuerpo. Se plantea así que, bajo esta superposición de derechos, es que cierto sector de la sociedad intenta comunicarse con la sociedad entera o aquella dentro de la cual este sector vive. Es como si en este afán de fragmentación social, los derechos humanos servirían más bien como reafirmación de estas fragmentaciones que como intento de conformar un ligamen con el resto de la sociedad, que por otro lado ya fue separada. Pues en este malestar que surge, cuando uno coarta el derecho común de un otro, más que acentuar un intento de acercamiento, se acentúa el límite que propone la función que cada sector lleva en la sociedad, mostrando así el poder que tiene el sector demandante, pero no por las características propias positivamente tomadas, sino por el efecto negativo que puede producir en el otro.

Trataremos de abordar más cualidades de todos los aspectos y dimensiones involucrados en esta contienda social. El ejercicio activo de los derechos humanos está ligado a la historia de la participación por parte de los diversos sectores en cuanto ellos $u$ otros han sido vulnerados en sus derechos. Derechos que realmente pertenecen al vínculo estrecho que una persona puede establecer con el goce y dignidad de la vida y con la convivencia tolerante con los otros.

El análisis del poder en términos de relaciones de fuerza nos permitiría establecer las tácticas y estrategias que se movilizan en los distintos sectores, enfrentados o no. Cada fuerza despliega un saber de sí más un saber del otro. La verdad ya no es una sola, ni tampoco es posible mantenerla como tal. Los juegos de verdad se abren al menos, como para que resista otras verdades posibles. Los sentidos en que cada verdad se apoya hablan de la historia, del camino recorrido para haber podido llegar a decirla cada una a su modo. El análisis de estos recorridos nos da las características de cada táctica y de cada estrategia. Los saberes proliferan en todos los campos, y la verdad ya no 
puede ser contada de una sola manera.

Foucault dice:

Por poder hay que entender la multiplicidad de las relaciones de fuerza inmanentes y propias del dominio en que se ejercen; el juego, los apoyos, los corrimientos, las estrategias que las tornan efectivas, y cuyo dibujo general toma forma en los aparatos estatales, en la formulación de la ley, en las hegemonías sociales. Hay que ser nominalista: el poder es el nombre que se presta a una situación estratégica compleja en una sociedad dada (Foucault, 1977: 112,113).

La vida deviene resistencia al poder cuando el poder tiene por objeto la vida. Es decir, que es mediante la vida con la que se puede ofrecer resistencia y entablar una relación de poder. Poner el cuerpo, realizar la movilización, concretar la movilización. Pero, esto no son más que los pedestales móviles de las situaciones sociales. Es necesario vislumbrar cuáles son los factores que si bien entran en juego en estos enfrentamientos sociales o de superposición de derecho, no salen a la luz. Ya que no dejan de formar parte de la estrategia necesaria que es necesario a utilizar frente a los problemas.

Los derechos humanos, su Declaración Universal, la adhesión estatal a los tratados internacionales, las demandas para que se cumplan con ellos y sus consecuentes atropellos se encuentran en una determinada sociedad en una situación estratégica; Foucault dice:

(...) las relaciones de poder son a la vez intencionales y no subjetivas. (...) están atravesadas por un cálculo; no hay poder que se ejerza sin una serie de miras y objetivos; la racionalidad del poder es el de las tácticas a menudo muy explícito (Foucault, 2002b: 115).

Toda estrategia de enfrentamiento intenta transformarse en una relación de poder, y ésta tiene por objetivo obtener una estrategia ganadora.

Así es factible pensar que

(...) los discursos son elementos o bloques tácticos en el campo de las relaciones de fuerza; puede haberlos diferentes e incluso contradictorios. A los discursos hay que interrogarlos en dos niveles: su productividad táctica (qué efectos recíprocos de poder y saber aseguran) y su integración estratégica (cuál coyuntura y cuál relación de fuerza vuelve necesaria su utilización) (Foucault, 2002b: 124).

La intención es vislumbrar a ese 'diagrama' del que los derechos humanos forman parte. Foucault dice

Con este análisis se trata de saber simplemente por dónde pasa la cosa, cómo pasa, entre quienes, entre qué puntos, de acuerdo con qué procedimientos y con qué efectos. No podría ser a lo sumo más que el bosquejo de una teoría, no de lo que es el poder, sino del poder. Es un conjunto de procedimientos, y sólo en este sentido, podríamos entender que el análisis de los mecanismos de poder pone en marcha algo susceptible de definirse como teoría del poder (Foucault, 2006: 16).

Es imprescindible definir cuál es la coyuntura de los discursos en tanto bloque táctico, y analizar a qué están unidos -indefectiblemente- la Declaración 
Universal, los derechos humanos, el sistema jurídico argentino, sus demandas y la jurisprudencia. Puede que observemos que su coyuntura sea su descuido y su ultraje, además de una extensa producción de saberes y lugares institucionalizados, a partir de estos ultrajes. O el despliegue y proliferación de ambos.

Los derechos humanos entonces poseerían un valor de verdad en relación con el hombre actual. No es de interés de esta investigación destacar cuál sería la verdad, sino cómo se va utilizando, cómo se van acomodando los diferentes elementos que constituyen a la realidad para obtener un efecto de poder. Tampoco es de interés de este trabajo destacar los efectos de verdad que en el discurso produce el sujeto supuesto saber para lograr destapar esa cesura que marca el acceso a lo simbólico (Lacan, 1969); sino, por el contrario, el interés radicaría en analizar los efectos de poder que produce un discurso estatutario descalificado o calificado en la conformación de la subjetividad del hombre actual. Los derechos humanos podrían funcionar muy bien en tanto bloque estratégico dentro de la modernidad.

El Doctor en Derecho y Ciencias sociales de la Universidad de Buenos Aires, Juan Antonio Travieso sostiene que:

La reforma constitucional de la República Argentina de 1994 se ha establecido un nuevo esquema en las relaciones entre el Derecho Internacional Público, el Derecho Internacional de los Derechos Humanos y el sistema jurídico interno. El próximo paso consistirá en la aplicación constante de la Convención Americana de Derechos Humanos en los tribunales y parlamentos de los sistemas jurídicos (Travieso, 1998: 31).

Esto significa que en los últimos años hay un denodado esfuerzo por jerarquizar los tratados internacionales que deben ser puestos en armonía con las normas de la Constitución de 1853/1860 y con la Reforma de 1994. A lo que agrega Travieso:

La cita de los precedentes jurisprudenciales es habitual en la práctica de los tribunales nacionales e internacionales. Los tribunales han construido la interpretación siguiendo un camino marcado por fallos. Un fallo es consecuencia directa de otro u otros. En todo sistema de derecho es imprescindible que haya un margen de predictibilidad del derecho, que no es trivial y forma parte de la coherencia que deben guardar los sistemas jurídicos. El rol de los tribunales internos para asegurar la efectiva protección de los Derechos Humanos no debe ser subestimado. Hay que insistir en la aplicación de las normas de la Convención Americana de Derechos Humanos en el orden interno, pues es en esos tribunales donde las garantías se invocan (Travieso, 1998: 18, 32).

Así, a medida que los tratados internacionales se concretan y toman vigencia, la internacionalización del derecho se hace más efectiva. La tendencia es a que exista un amplio campo de jurisprudencia, lo que significa que haya un libre comercio de interpretación de normas vigentes. Refirièndose a Bidart Campos, Travieso dice que:

(...) concluye que "un sistema de derechos en un Estado democrático debe interpretarse de tal modo que logre completud y quede cerrado a través de dos fuentes: la interna y la internacional. Sin duda, la jurisprudencia de la Corte 
Interamericana de Derechos Humanos, es la voz de los silencios de la Convención Interamericana de Derechos Humanos. (Travieso, 1998: 21).

La Declaración Universal fue el movimiento estratégico necesario, casi incondicional, de un Dispositivo de Seguridad para el que son útiles los derechos humanos en tanto código discursivo. Especialmente aquellos derechos humanos que devienen de la matriz política de las Ciencias del Hombre: las nuevas disciplinas humano-científicas de la biorregulación, del biopoder; en tanto permiten racionalizar, sobre la base de registros de demanda, las políticas y las economías de un Gobierno, de un Estado, para con su población. Es decir, gobernar sin caer en un totalitarismo racionalista a partir de un conjunto de reglas humanitariamente aceptables, las cuales desprenden todo un bagaje de saber incuestionable por su calibre de saber del hombre, a veces humanista. Condiciones mínimas para poder vivir en dignidad, aportes obligatorios y necesarios para que la infancia se desarrolle como infancia, establecimiento de un estándar mínimo sobre las condiciones de pena privativa de libertad en cárceles, indicadores sobre la discriminación, seguridad sobre la reproducción y en la expresión.

La temática del hombre, a través de las Ciencias Humanas que lo analizan como ser viviente, individuo que trabaja, sujeto hablante, debe comprenderse a partir del surgimiento de la población como correlato de poder y objeto de saber. El hombre, tal como se lo pensó y definió a partir de las llamadas ciencias humanas del siglo XIX y tal como lo hizo objeto de su reflexión el humanismo de esa misma centuria, no es otra cosa que una figura de la población. A partir del momento de que la contracara del gobierno, del arte de gobernar, apareció la población, podemos decir que el hombre fue a ella lo que el sujeto de derecho había sido al soberano (Foucault, 2006: 108).

El saber que desde los derechos humanos se desprende en la era liberal, es al hombre lo que de natural tenía la vida del hombre para estar disponible a su rey en la Edad Media.

Las prácticas de subjetivación son también formas de objetivación, es decir, de los modos en que el sujeto, o el hombre, ha sido objeto de saber y poder, para sí mismo y para los otros. El concepto de gobierno marcaría el primer deslizamiento, en Foucault, de la analítica del poder a la ética del sujeto. La problemática de la "gubernamentalidad" señala la entrada de la cuestión del Estado al campo de análisis de los micro-poderes. No excluye el Estado, pero tampoco se le subordina. El manejo de los procesos biosociológicos de las masas humanas, a diferencia de las disciplinas, implica el aparato estatal. Se inscribe en el espacio abierto por el problema del biopoder.

Gobernar consistiría en conducir conductas. Y en relación consigo mismo, el gobierno, trataría de dominar, por ejemplo, demandas y ofertas, ganancias y pérdidas, enfermedades psíquicas o biológicas, hambre y derroche, adicciones y abortos, protestas $u$ orden, salud y enfermedad, conocimiento o poder, expropiaciones y producciones. Para Castro (2004), las formas de objetivaciónsubjetivación se encuentran entre estos dos ejes.

Este saber desplegado además de producir una determinada subjetividad argentina, ayuda a producción en materia de las ciencias humanas argentinas que estudia, investiga y diagnostica a este argentino representado a través de sus formas de trabajar, vivir y hablar. 


\section{Los Derechos Humanos como Dispositivo.}

Las implicancias que tiene la defensa por los derechos humanos en múltiples campos, como lo son el jurídico, el de las ciencias humanas, el de la genética y la sexualidad, el de la política y el de la economía, nos permite analizarlos como un factor bisagra en nuestro análisis en términos de biopoder,

Dentro de la tríada conceptual soberanía-disciplina-gestión gubernamental, los derechos humanos constituyen un elemento funcional como formadores de los procesos de subjetivación, y como determinantes en los algunos de los procesos de gestión gubernamental a la hora de definir decisiones políticas de Estado. Estas decisiones comportan un factor de subjetividad en cuanto que objetivizan a los ciudadanos en tanto sujetos jurídicos.

\section{Las ciencias humanas y su relación con los derechos humanos.}

Para Foucault, el campo de las Ciencias Humanas, el de la psicología, la sociología, la teoría de los mitos y la literatura, "es un cuerpo de conocimientos, un conjunto de discursos que toma por objeto al hombre en lo que tiene de empírico" (Foucault, 2002: 334). El campo epistemológico de estas ciencias no ha sido prescrito de antemano, pero se ubica en el espacio de redistribución general de la episteme moderna. La dimensión de ésta, dice Foucault, es un dominio abierto y voluminoso de acuerdo con tres dimensiones: las ciencias llamadas exactas (matemática y física), las ciencias empíricas (las del lenguaje, de la vida, de la producción y distribución de las riquezas), y la reflexión filosófica que se desarrolla como pensamiento de lo mismo.

Lo que Foucault denomina el triedro de saberes de la episteme moderna está formado por las ciencias llamadas exactas (cuyo ideal es la concatenación deductiva y lineal de las proposiciones evidentes a partir de axiomas). (...) Cada una de estas tres dimensiones está en contacto con las otras dos. Por un lado, entre las ciencias exactas y las ciencias empíricas existe un espacio común definido por la aplicación de los modelos matemáticos a los modelos cualitativos. Surgen de este modo los modelos matemáticos, lingüísticos, biológicos y económicos. Por otro lado, entre la analítica de la finitud y las ciencias empíricas encontramos todos los esfuerzos de formalismo, y entre la analítica de la finitud y las ciencias empíricas encontramos las filosofías que tematizan los objetos de éstas como a priori objetivos: las filosofías de la vida, de la alienación y de las formas simbólicas, por ejemplo (Castro, 2004: 170).

La dificultad con que se encuentran las ciencias humanas se debe a la familiaridad con la filosofía, su precariedad en cuanto el modelo usado y sustraído de los otros dominios de saber (la formalización de la mathesis), y su carácter secundario y derivado de las dimensiones del hombre (que habla, que vive y que trabaja); sumado a esa pretensión a lo universal que siempre caracterizó al pensamiento humano.

Lo que según nuestro autor define a las ciencias humanas es la manera en que éstas se sitúan, por un lado, en relación con las ciencias empíricas y, por otro, en relación con la analítica de la finitud. Su espacio está determinado de cuanto en el hombre hay de positivo (el trabajo, la vida y el lenguaje) y lo que posibilita 
al hombre saber qué es la vida, el trabajo y el lenguaje. Las ciencias humanas se ubican así en el dominio que va de la positividad del hombre a la representación de esta positividad, de las empiricidades a la analítica de la finitud (Castro, 2004: 170).

Con respecto a su "positividad" y también respecto a las relaciones surgidas entre ellas y las representaciones, Foucault distinguió tres modelos. Uno de ellos, el tercero, es el modelo constitutivo, que desempeña el papel de categorías a través de las cuales es posible construir como objeto un grupo de fenómenos. A partir de los fenómenos de la biología, él extrajo la categoría de función y norma. Desde la economía surgieron las categorías de conflicto y regla, y a partir de la filología, emergieron las categorías de significación y sistema. Todos estos conceptos y estructuras son tomados de nuevo en el volumen común de las ciencias humanas, de ahí que sea difícil encontrar los límites de los objetos y definir los métodos propios de la psicología, la sociología y la antropología. Ya que cada una está compuesta en el intersticio de cada dimensión positiva y enfatiza a la vez una que otra representación que le da estructura y la clasifica.

Surge aquí la pregunta acerca del aporte que realizan las ciencias humanas a los derechos del hombre. O mejor expresado, qué anudan aún más los derechos humanos en este campo de interrelación, ya que éstos en su dimensión histórica y discursiva integran a nivel discursivo el trabajo, la vida y el lenguaje.

De esos tres aspectos se desprendieron todos los artículos contemplados en la Declaración de Viena de 1948, y en su globalidad, respondieron a cierta reflexión filosófica sobre estas mismas dimensiones (art. 23, art. 25, art. 16 de la Declaración Universal de DDHH). Es más, el fenómeno de proliferación que se produjo, en vez de englobar, de terminar de encerrar todo un campo estableciendo límites claros de dominio, permitió que se desarrollasen nuevas líneas de interrelación, abrió un nuevo espectro por los cuales los tres dominios primeros, aquellos que constituyen la episteme moderna, pudieron poder jugar con nuevas herramientas.

Los derechos humanos como efecto de las nuevas herramientas, como nuevos espacios de saber, que el hombre encontró, creando, utilizando en su relación con el trabajo, la vida, el lenguaje, habla de este movimiento centrífugo, de éste juego de interrelaciones de este triedro. $Y$ sobre todo cuando la muerte y la vida entran como factor predominante en la vida social, los derechos humanos posibilitan describir los sentidos políticos de las muertes, la significación moral y económica de la vida, la ética económica de prácticas sexuales o prácticas en el campo de la salud.

Así como las Ciencias Humanas enmarcan lo que no es formalizable matemáticamente, son el envés de las ciencias empíricas y a la vez propician a una reflexión filosófica del hombre mas nunca llega a su estatuto; los derechos humanos como Dispositivo engloban también a todo hombre que no trabaja, que no vive y que no habla (o a alguno de los tres). Los derechos humanos, como dispositivo, permiten establecer nuevas condiciones que imponen los saberes empíricos y positivos (económicos, jurídicos, sociales) transformándose en instituciones que regularizan o subjetivizan determinadas situaciones con vocación de integración. 
El campo de las Ciencias Humanas ayuda a esta proliferación de saber y de técnicas, de discursos y herramientas, coopera en el movimiento centrífugo de nuestra episteme moderna. Oxigena las relaciones entre los diferentes elementos. Los derechos del hombre son un elemento más de las ciencias humanas, es decir, aportan a la representatividad que se tiene del hombre. Y a la vez, tienen la potestad de poder intervenir o al menos cuestionar el campo de los otros conocimientos contemporáneos, como lo pueden hacer sobre la economía, sobre la medicina y la biología, y también sobre la construcción del lenguaje. Son la contrapartida de la impotencia de las ciencias humanas de hacer ciencia positiva; distinguiéndolo del hombre-objeto, haciéndolo sujeto y/u ofreciéndole subjetividad:

Identificación analítica, sujeción, subjetivación: esto caracteriza los procedimientos de individuación que serán efectivamente puestos en práctica por el pastorado cristiano y sus instituciones. La historia del pastorado implica por lo tanto toda la historia de los procedimientos de individualización humana en Occidente. Digamos además que es la historia del sujeto. (Foucault, 2006: 219).

Ya entonces no se trata de construir solamente este objeto de saber llamado hombre, individualizado a través de la disciplina, economizando la energía del control, a través de la anátomo política del poder; sino también de constituir una verdad atravesados por los sentidos de la vida y la muerte colectivas en términos de relación con la historia. Es decir, también se construye la representación que se tiene del hombre en tanto colectivo, para lograr la regulación de conductas a través del conocimiento estadístico que se obtiene. En este caso, es la biopolítica el concepto que permite captar a dinámica de las relaciones de fuerza, la economía del poder.

Los derechos humanos se mueven con un cualidad de efectividad táctica a nivel político y de integración estratégica, desplazándose de acuerdo con su posibilidad, a su condición: de ahí que exista una Declaración Universal; la creación de diferentes organismos dentro de las Naciones Unidas; la creación de Organizaciones No Gubernamentales; las oficinas públicas de Derechos Humanos; el voluntariado de las diversas ONG; el saber científico y no científico vinculado y que emerge en éstas; los discursos políticos con fuerte ideología humanista; las movilizaciones multitudinarias; por ejemplo. Sería como que configuran un dispositivo de seguridad en tanto cumplen con la posibilidad de diagramar la situación de tensión moderna del Estado de su población, tensión que hace posible describir los factores que intervienen en el estilo de identificación social con nuestra era de la razón y con la mercancía percibida como ineludible. Para Foucault, la dinámica política y la dinámica como ciencia física son más o menos contemporáneas.

\section{Nuestra gubernamentalidad.}

El análisis de las relaciones de poder nos permite seguir caracterizando los procesos de subjetivación que se van desprendiendo, las tácticas móviles y las estrategias cambiantes.

Ahora bien, en cuanto a la posibilidad de ejercer la violencia política, Foucault enfatiza la capacidad que tienen los gobernados de sublevarse y/o de hacer la 
revolución. Considera que sublevarse es

(...) el movimiento mediante el cual un solo hombre, un grupo, una minoría o un pueblo entero dice: «no obedezco más», y arroja a la cara de un poder que estima injusto el riesgo de su vida — tal movimiento me parece irreductible(Foucault, 1979: 1).

Para él, las sociedades se mantienen vivas y los poderes no son absolutos y eternamente totalitarios. Porque aún después de doblegarse, de aceptar las coerciones, las agresiones y amenazas que el poder impone, los dominados tienen la capacidad de resistir, y "cabe la posibilidad de ese movimiento en que la vida ya no se canjea, en el que los poderes no pueden ya nada y en el que, ante las horcas y las ametralladoras, los hombres se sublevan" (Foucault, 1979: 1).

Foucault diferencia entre sublevación y revolución, acuñando este último término para el movimiento por el cual se legitima una sublevación al interior de una organización política en particular. La revolución ha tomado lo más conveniente de la sublevación, ha definido las leyes de su despliegue y su desarrollo fijándole condiciones previas, objetivos y maneras de cumplirse (Foucault, 1979). Y esta direccionalidad o domesticación política de la sublevación no es para evitar un cambio en el manejo del poder que devendría en otra relación de poder entre nuevos dominadores y dominados; sino para evitar el derrame completo de sangre tanto de los dominados como de los dominadores lo que supondría una reorganización en la economía del poder diferente.

No es que se resalte y enaltezca la posibilidad de "el derecho a sublevarse" como única forma fidedigna de decir basta a un poder con el que se está en desacuerdo, e ir a las armas o rechazar cualquier tipo de diálogo. Tampoco de desvalorizar a la revolución en sí, hablando en términos de lógica histórica ya que, después de todo, se puede pensar y sentir que siempre habrá dominadores y dominados. El establecimiento de esta diferencia es para analizar cada paso particular histórico y caracterizarlo, y hasta juzgarlo políticamente, según sus condiciones. "Hay sublevación, es un hecho; y mediante ella es como la subjetividad (no la de los grandes hombres, sino la de cualquiera) se introduce en la historia y le da su soplo" (Foucault, 1979: 2). Foucault valora el hecho mismo de la sublevación.

Los escritos de Foucault, son como herramientas bélicas, cuya instrumentalización en el combate no está dada por el valor de verdad al cual acude o emerge, sino por la intensidad y cualidad de los efectos políticos que se esperan de ellos.

Foucault fue testigo del proceso que llevó al triunfo a la Revolución Iraní en enero de 1979. Por entonces, saludó con entusiasmo la rebelión popular contra el régimen dictatorial del Sah; posteriormente, y ante el cariz integrista tomado por la Revolución, se mostró muy crítico frente al nuevo régimen. Fruto de esta experiencia son las citas en cuestión, un artículo periodístico en el que reflexiona sobre la Revolución triunfante en Irán en enero de 1979. Foucault escribe luego de la victoria de la Revolución, cuando el ayatolá Ruhollah Jomeini (1902-1989) ya había alcanzado el control del nuevo gobierno. Esto es importante, porque ya estaba claro cuál iba a ser la orientación del nuevo régimen, en el que la línea teocrática había logrado la primacía sobre las 
demás: con la misma intención opresora que el régimen anterior. Es por ello que Foucault modifica su posición inicial de apoyo a la Revolución ya que, si antes estaba en contra de la amputación de manos, luego lo estuvo contra las torturas de la Savak.

La sublevación es más un movimiento ético, una respuesta visceral contra la opresión, que un movimiento político. La política (cualquier política, ya sea la de los opresores o la de los oprimidos) se caracteriza fundamentalmente por construir diferentes tipos de organización para llevar adelante determinados objetivos. En el caso de la "sublevación", se trata de una reacción intensa de quien no quiere obedecer más; está dirigida contra la opresión en general, no contra una opresión determinada. En este sentido es a-histórica, ya que si bien es capaz de derribar a un régimen opresor, es incapaz en cambio de construir un orden.

La revolución en el sentido foucaultiano, en cambio, intenta dirigir la sublevación dentro de "condiciones previas, objetivos y maneras de cumplirse" (Foucault, 1979). Significa el esfuerzo por introducir por la fuerza a la "sublevación" en la historia, para de ese modo domesticarla y ponerla al servicio del poder. Hay que tener en cuenta que toda forma de saber es una forma de poder; de ello se deriva que la constitución de un saber de la "sublevación" implica forzosamente el sometimiento de la sublevación al poder.

Estamos de acuerdo con Foucault en que la acción de los oprimidos es la óptima garantía y variable única para que la opresión no se fortalezca. Foucault, en cuanto al poder, también dice que

Las reglas nunca son lo suficientemente rigurosas como para limitarlo: y los principios universales nunca lo suficientemente estrictos para desasirlo de todas las ocasiones en las que se ampara. Al poder hay que oponerle siempre leyes infranqueables y derechos sin restricciones (Foucault, 1979: 2).

Foucault buscó salir de la concepción jurídico-política de la soberanía, la cual explica el proceso por el cual las personas se convierten en ciudadanos, en virtud de dar algo de sí al Estado. La existencia del Estado queda justificada en términos de la superación de las diferencias y los anhelos individuales, por la cual se da lugar a un espacio de civilidad y paz regido por la voluntad y el bien común. El Estado representa la finalización de la guerra y de la obediencia por mandato divino. Y sólo la guerra se reemprenderá contra aquellos que quebranten los fundamentos del pacto político. El matiz de Foucault fue el reconstruir un discurso que vislumbre no sólo la falsedad del ideal de la universalidad jurídica y política, sino también la utilización de esta falsedad al servicio el ocultamiento de la escisión social entre los vencedores y los derrotados.

La sociedad se comprende como compuesta por nódulos de poder diferenciados, cuyos intereses, movimientos, alianzas y conflictos constituyen la historia del Estado y de sus instituciones. La emergencia tácita y posterior reconocimiento de la existencia de las partes en conflicto inaugura un planteamiento binario de la realidad política, en el que se combinan las referencias a la guerra y a los grupos sociales implicados en ella. El orden del saber, la producción de sentidos y significados en términos éticos, estéticos, políticos, penales, se despliega como una pieza del engranaje de la organización política, que busca la vinculación jurídica de los individuos. Es 
decir, la obediencia bajo el orden de contrato social. Lejos de ser un instrumento neutral e indiferente a los enfrentamientos de poder que fundan una homogeneidad o un consenso, la historia funciona como un operador y un intensificador del poder, que termina por encontrar sus propias resistencias. La «verdad» del discurso aparece como un elemento finalmente subordinado a sus efectos prácticos, es decir, político, que es el que otorga realidad y densidad política al sistema de enunciados empleados en la batalla. En términos foucaultianos, la genealogía no se orienta a la implantación de una verdad más profunda o mejor fundamentada, sino a la elaboración de una «historia-insurrección» (López Álvarez, 2006).

En el contexto de la transformación de las estructuras administrativas y judiciales que hacen emerger a los Estados modernos, se coloca el interés en las formas en la universalización de las técnicas jurídico-penales, mostrando su sentido en el orden de las necesidades estratégicas. En estos términos, el derecho no es antónimo de guerra, ni tampoco sinónimo de justicia; sino que constituye la herramienta por la cual se puede conducir una guerra de forma ordenada, singular y reglamentada.

Foucault pensó más en la justicia en términos de lucha social, que tomar a la lucha social cómo vehículo hacia la justicia. Para él, la revolución sólo es efectiva si las masas pueden fabricar formas y modelos de retribución, castigo y pena que no tengan elemento en común con aquellas formas con las cuales se impidió levantamiento alguno. El que se subleva no pide nada al Estado soberano, más bien conduce a la guerra en contra del Estado, quiere salir de éste y que el Estado se salga de él. El sublevado hace que se reconozca su poder ante otro poder al cual no legitima.

Rescatando estas diferenciaciones que realizó Foucault, y para analizar nuestro caso de la Argentina, podemos decir que hubo variedad en la modalidades de resistencias que se desplegaron ante el poder dominante y opresor. Entre las resistencias que más cobraron importancia e influencia en el medio político y jurídico, éstas no fueron ejercidas con una acción de neto corte de "sublevación" ni con características de puras de "revolución". Si bien hubo desobediencia ante el poder opresor, personas y grupos arriesgaron su vida y la de los familiares, e incluso el fin de esta desobediencia fue la de sustituir a los jefes de mando, ésta demanda fue mediante el pedido expreso del regreso al ejercicio democrático. Es decir, la mayoría de las demandas ejercida por los grupos involucrados en la resistencia explícita, no estuvo la demanda de otro tipo de organización socio-política o la petición de conformar otro Estado aparte. Más bien sus objetivos fueron los señalados por Foucault en cuanto que al poder hay que oponerle leyes infranqueables y derechos sin restricciones, con modalidades de manifestación para que el poder sepa que hay límites para su acción de dominación.

Rescatamos la posición de estos grupos a valorar al sistema de derecho como garantía a poder protestar, y a poder enjuiciar cuando el poder comete no simplemente opresión, sino también delitos. Sean de la dimensión que sean, tanto los pertenecientes a los estipulados en el código penal como los de extrema gravedad como los denominados delitos de lesa humanidad. Y también, porqué no, el derecho a poder desobedecer. Reaccionaron las "madres de plaza de mayo" con marchas con pañuelos blancos en sus cabezas ante el despliegue del aparato militar. Dijeron basta, no al sistema de poder del 
Estado de Derechos, sino al sistema de poder de facto. Enaltecieron al derecho como modo de reivindicación de los grupos que son oprimidos y marginados, y que a veces son minoritarios.

En este sentido, la justicia no se hace más justicia porque es justa y a cada cual le toca la responsabilidad o castigo divinamente buscado, sino es justicia porque se busca la aplicación del proceso que el Estado de Derechos dispone.

\section{La emergencia social.}

Ahora bien, ¿cómo hacer para poder incluir este análisis de mínimo de intervencionismo económico y máximo jurídico a los procesos de subjetivación que se promueven desde la política de derechos humanos? Como dijimos anteriormente, es a la vez que se fue desarrollando una subjetividad que incluyó en la vida social Argentina el aspecto empresarial o el aspecto económico como definitorio para muchos asuntos (el valor de la moneda como nuevo valor social); se fue desarrollando toda una subjetividad que tuvo que ver con la consolidación de otra verdad, la verdad de violación a los derechos humanos que, sin embargo, durante muchos años no se aceptó como real.

Sea aceptada o no aceptada esta verdad, las subjetividades tuvieron caminos diferentes por los cuales surcaron su construcción. Unas subjetividades proclives al silencio y a la complicidad del miedo, y otras en las que, la búsqueda irrenunciable, promovió la esperanza, la solidaridad y la socialización de los problemas acuciantes, pero siempre condicionadas por la legislación económica que no amparó ni integró a la totalidad de la población. Llegó estas últimas formas de subjetividades a acusar al régimen represivo de ser la causante de los agravios que van desde los males menores (como no poder acceder a un trabajo estable) hasta los más graves (como lo es la máquina mortificante de las cárceles). Se trabaja sobre estas políticas de Estado, pero este cuestionamiento sólo llega a las cámaras judiciales, en donde se responsabiliza al Estado de no haber respetado los derechos humanos, más no se responsabiliza a los civiles ni se derogan las legislaciones que llevaron a cabo la implementación del sistema que hizo que estos derechos no puedan ser ejercidos, no sólo los de vida y la dignidad, sino también los económicos y culturales.

Los organismos internacionales de créditos contribuyeron, planificaron y otorgaron desembolsos, produjeron el despilfarro y la pérdida de la población argentina de sus derechos sociales. Estos, alguna vez, estratégicamente ocuparon una posición económica y social que apuntalaba trascendentalmente al trabajador asalariado, al jubilado y a la familia en una identidad que estaba en relación directa e inter-generacionalmente al otro conciudadano.

Los derechos humanos en nuestro caso abrieron el ciclo de una nueva regulación del Estado argentino cuando éste impulsó medidas que enaltecen a la libertad dentro del campo económico y cívico. A la extremada defensa de la libertad económica le correspondió su determinado saldo social y cultural. Para unos este saldo se denomina memoria, verdad y justicia; para otros es sólo la incansable e inacabable presencia de la pobreza, y otros lo consideran como el silencio del excedente de unos pocos.

Las regulaciones de la gubernamentalidad Argentina también son alimentadas 
por los litigios en materia de derechos humanos y en materia de derecho comercial. Los derechos humanos son un mecanismo que es axiológico porque integra los aspectos universalistas de la vida, el trabajo y el lenguaje, y son mercantilistas porque reciben los impactos de una verdad que el mercado, que con su lógica de acumulación y producción inocula todo lo que toca. Es también jurídico porque determina la condición de los seres humanos, en tanto que persona individual, colectividad o minoría, y en tanto de nuevas tipologías y clasificaciones a considerar.

Es decir, los derechos humanos se encuentran en una situación privilegiada de acuerdo con la complejidad de la realidad actual, por lo que los consideramos un dispositivo de seguridad en términos de relaciones de poder, porque permiten ubicar táctica y estratégicamente cualquier subjetividad que se resienta por la tensión de la era moderna.

\section{Bibliografía:}

Castro, Edgardo (2004). El vocabulario de Michel Foucault. Buenos Aires: Universidad Nacional de Quilmes.

Foucault, Michel (1977). ¿Van a extraditar a Klaus Croissant? En Le Nouvel Observateur, No 679, 14-20 de Noviembre 1977.

Foucault, Michel (1979). ¿Es inútil sublevarse? En Le Monde, № 10.661, 11-12 de mayo de 1979, págs. 1-2.

Foucault, Michel (2000). Defender la Sociedad. Buenos Aires: Fondo de Cultura Económica de Argentina.

Foucault, Michel (2002). Las palabras y las cosas. Una arqueología de las ciencias humanas. Buenos Aires: Siglo XXI Editores Argentina S.A.

Foucault, Michel (2002b). Historia de la Sexualidad. Volumen 1: La Voluntad de Saber. Buenos Aires: Siglo XXI Editores Argentina, S.A. de C.V.

Foucault, Michel (2006). Seguridad, territorio, población. Buenos Aires: Fondo de Cultura Económica de Argentina, S.A.

Hobbes, Thomas (1981). El Leviatán. México: Publicaciones Cruz O.S.A.

Lacan, Jaques. (1984). El Seminario de Jacques Lacan. Libro 11. Los cuatro conceptos fundamentales del psicoanálisis 1964. Buenos Aires: Ediciones Paidós.

López Álvarez, Pablo (2006). La guerra infinita, el enigma de la sublevación. Michel Foucault y la interpretación bélica de la política. En Nicolás Sánchez Durá, La Guerra, pp. 161-184. Valencia: Pre-textos.

Travieso, Juan Antonio (1998). Derechos Humanos y Jurisprudencia. Doctrina y legislación argentina e internacional. Buenos Aires: Editorial Universitaria de Buenos Aires. 